Portland State University

PDXScholar

6-15-2018

\title{
"I didn't want to say it's a bad thing": Supporter Experiences with Autistic Patients in Healthcare
}

\author{
Mirah L. Scharer \\ Portland State University
}

Follow this and additional works at: https://pdxscholar.library.pdx.edu/honorstheses

\section{Let us know how access to this document benefits you.}

\section{Recommended Citation}

Scharer, Mirah L., "'I didn't want to say it's a bad thing": Supporter Experiences with Autistic Patients in Healthcare" (2018). University Honors Theses. Paper 602.

https://doi.org/10.15760/honors.612

This Thesis is brought to you for free and open access. It has been accepted for inclusion in University Honors Theses by an authorized administrator of PDXScholar. Please contact us if we can make this document more accessible: pdxscholar@pdx.edu. 
Running Head: “I DIDN'T WANT TO SAY IT'S A BAD THING:” SUPPORTER

EXPERIENCES WITH AUTISTIC PATIENTS IN HEALTHCARE

"I didn't want to say it's a bad thing:" Supporter experiences with Autistic patients in Healthcare

by

Mirah Scharer

An undergraduate honors thesis submitted in partial fulfillment of the

requirements for the degree of

Bachelor of Science

in

University Honors

and

Psychology

\section{Thesis Advisor}

Dora Raymaker, $\mathrm{PhD}$ 


\begin{abstract}
Background

Due to the characteristic traits associated with autism, many autistic adults need the help of a supporter during healthcare events. No research has been done on the supporters of autistic adults and how they are making meaning from their experiences.

\section{Objective}

Investigating the experience of the supporters' navigating negative healthcare events while supporting an autistic adult will assist in filling the gap and focus my research.

\title{
Method
}

I partnered with the community based participatory research (CBPR) group the Academic Autism Partnership in Research and Education (AASPIRE) and used a CBPR approach to conduct a qualitative latent thematic analysis. I extracted 16 semi-structured and open-ended supporter stories about negative experiences in healthcare settings from larger interviews, and analyzed them at a latent level. Triangulation verification was used as an inclusive CBPR process and involved three AASPIRE partners.

\section{Results}

We used 16 semi-structured interviews with supporter participants who had experience supporting autistic adults in healthcare settings. Latent themes extracted from supporter responses included the supporter advocating for the patient, the supporter knowing the patient, and the supporter minimization of the negative healthcare experience. Interplay between the themes led to discussion with AASPIRE community partners regarding the deficit framework the medical model takes on disability. 


\section{Conclusion}

The presence of advocation for and knowing the patient on an intimate level influenced the frequency of minimization within the negative event. Minimization is a coping mechanism used to downplay negative affect or feelings of being overwhelmed. The medical model may be a driving force behind the use of minimization as a technique of reducing negative affect when coupled with the practice of dehumanization. Paid disability support staff should be required to become familiar with the autistic adult patient's medical history and accommodations prior to the healthcare appointment. This allows for the supporter to know the patient and better advocate for them

Keywords: supporter, Autistic adults, autism, healthcare, minimization, advocacy, CBPR 


\section{I didn't want to say it's a bad thing:" Supporter experiences with Autistic patients in}

\section{Healthcare}

\section{Introduction}

Studies have shown that patient emotional and physical health can be improved with good physician-patient communication (Stewart, 1995). Likewise, poor communication between patient and provider can create barriers to effective healthcare (Stewart, 1995). Adults on the autism spectrum often face obstacles regarding communication. American Psychiatric Association's Diagnostic and Statistical Manual, Fifth Edition (DSM-5) provides criteria for the diagnosis of Autism Spectrum Disorder (ASD). One of those criteria is persistent challenges in social communication and interaction across multiple contexts (Association, 2013). These challenges often manifest as speaking and non-nonspeaking communication that does not adhere to social norms. Again, the DSM-5 states that an "abnormal social approach" and a "failure to initiate or respond to social interactions" are criteria for an ASD diagnosis (Association, 2013). A study by the Academic Autism Spectrum Partnership in Research and Education (AASPIRE), explored the challenges faced by autistic adults in the healthcare setting and noted that "challenges related to verbal communication skills were prominent... but differed in nature depending on the individual's communication needs and strengths" (C. Nicolaidis et al., 2015). Accommodations are adjustments made to allow for the equal access to the same benefits that are available to everyone (ODEP (Office of Disability Employment Policy) (n.d.). Supporters are a solution to ASD patient-provider communication barriers. Supporters are people that act as a tool of accommodation. 
It would seem that supporters offer a potential solution to the communication disability of autistic adults ${ }^{1}$. However, little research to date has been done on the experience of supporters of autistic adults. The lack of studies done on supporter experience is a gross absence in research involving autistic adults and their supporters. This is especially true because supporters have been quoted (in another study focused on autistic patient perspectives, not supporter experiences) as indicating that they "had been responsible for the majority of the communication with the healthcare provider during the [autistic] adult's healthcare visit" (C. Nicolaidis et al., 2015). This indicates that supporters are already supporting individuals, but we do not know how they are managing challenging healthcare situations. Therefore, I aim to fill this gap in literature by doing a qualitative analysis that investigates the experience of supporters' navigating negative healthcare events while supporting an autistic adult will assist in filling the gap and focus my research.

\section{Positionality Statement}

As an allistic (or not autistic) college-aged person, I have been in situations where I've gone to my primary care provider and felt that my needs were not met due to a communicationrelated challenge. However, I do not know what it is like to have a communication-related disability, such as autism, and go to see my primary care provider about my healthcare needs. I also do not have the life experience to understand what it is like to be a supporter of an autistic person in any setting, let alone a healthcare situation. Given my positionality as an allistic individual who has no experience supporting an autistic adult and the gap in the literature around supporters, I am excited to explore the experience of the supporter while supporting an autistic person within a negative healthcare situation.

\footnotetext{
${ }^{1}$ We use the term "autistic adults" as many individuals on the autism spectrum prefer the use of identity-first language to person-first language. For more information, see http://autisticadvocacy.org/identity-first-language/.
} 


\section{Research Context}

This research study was done with and through the Academic Autism Spectrum Partnership in Research and Education (AASPIRE), a community based participatory research (CBPR) team made up of academics, Autistic community members, supporters, and clinicians. CBPR is used "...to enhance understanding of a given phenomenon and the social and cultural dynamics of the community, and integrate the knowledge gained with action to improve the health and well-being of community members" (Israel, Schulz, Parker, \& Becker, 1998). AASPIRE approaches all of its research projects using CBPR. Using CBPR within our research employs equal opportunity to work as partners in the "development, implementation, and dissemination of research that is relevant to the community" (Nicolaidas, 2018).

\section{Methods}

My study is based on research previously done by AASPIRE (C. Nicolaidis et al., 2013; C. Nicolaidis et al., 2016; C. Nicolaidis et al., 2015) in a research study that investigated the experience of Autistic adults, their supporters, and physicians in healthcare settings. That study interviewed autistic adult patients, supporters, and physicians who have/do care for individuals on the autism spectrum. The interviews were analyzed with a focus on patient experience within the healthcare event. Supporter interviews included supporters who were/are direct service providers or family members. I used the supporter interviews to conduct my research.

To be a participant in the study, participants had to be US residents, at least 18 years of age, and communicate in written or spoken English or American Sign Language (C. Nicolaidis et al., 2015). More specifically, the supporters also had to have had experience supporting an autistic adult in a healthcare setting. Recruitment for the supporters was done through local and national autism-related organizations and disability services professional groups (Nicolaidis et 
al., 2015). The final sample of supporters equaled 16 supporter interviews (12 family supporters and 8 disability service providers, some in both roles). The interviews consisted of topics that focused on positive and negative experiences with healthcare, perceptions of how being on the spectrum affected care, and recommendations for improving care (Nicolaidis et al., 2015).

I extracted an individual question from each interview regarding a negative experience while supporting an autistic adult patient, and then analyzed them with latent thematic content analysis using an inductive approach. To break this down, qualitative content analysis is a "method to classify written or oral materials into identified categories of similar meanings" (Ji Young Cho, 2014). The identified categories of similar meanings in this context refers to the extraction of themes within the narrative. The themes can be from either "explicit or inferred communication" and in this study we used inferred or latent communication (Ji Young Cho, 2014). Using an inductive approach to qualitative research simply refers to the approach "that primarily use detailed readings of raw data to derive concepts, themes, or a model through interpretations made from the raw data by an evaluator or researcher"(Thomas, 2006). More simply, the inductive approach allows "research findings to emerge from the frequent, dominant, or significant themes inherent in raw data" (Thomas, 2006).

I chose this question ("Have you had any bad or difficult experiences supporting $\mathrm{x}$ in healthcare settings?") to meet two aims: to focus and narrow this study to a specific type of event (perceived negative) and to explore a specific area of how supporters are making meaning of their experience. The content of the participant's answer was analyzed with the frames of looking for ways that the supporters were making meaning from their observations of a negative event and how the supporters were interacting with those reflections. The inclusion criteria were that the content must be regarding the self-identified negative event and the content must include 
an event that involved the supporter and a patient with a healthcare setting. Applying these frames and inclusion criteria to the content allowed for the content to be paired down to allow for more focused analysis with more depth of discussion and real-world connections.

While I completed my analysis, I chose one other person to complete the same analysis separately. By choosing another person to complete the same analysis, I began the process of inclusive triangulation verification. Triangulation verification is "the use of multiple sources to contrast and compare study data to establish supporting and/or contradictory information" (Roller, 2014). Inclusivity or community engagement comes into practice when one of the "multiple sources" is a member of the community being affected. The other coder (Rebekah Hunter) is an autistic woman who has been training in qualitative analysis methods and thus is a qualified individual to be a second coder in this study. Once we both finished our analysis of the narratives, we came together to review our findings as the first part of triangulation verification. Upon reviewing our findings, we both came to realize that we had found similar themes and ideas, which indicated that the themes found were accurate to what was occurring within the context of the interviewee's narrative. My partner found more in-depth details around ableism, autism discrimination, and the use of stigmatizing language. Whereas I found more latent content concerning how the interviewees were responding and what they really meant in those responses. Upon discussion of these inconsistences, we were able to reconcile and come to the conclusion that our individual and unique perspectives offer us different insights into latent content. While neither were wrong, we just noticed different (yet accurate) parts of the narrative. I integrated her insights with mine and the resulting themes included both. Rebekah's insights provided a perspective I was missing as an outsider, giving a more complete and richer perspective of each theme. 
After the initial analysis and inclusive verification was complete, I requested the topic of my thesis to be included in an AASPIRE team meeting to solicit volunteer engagement from our community partners. Their (the AASPIRE team partners) life, work, and/or scientific experiences make them not only qualified to verify my findings, but also give them a voice in this work. The inclusion of community partners in all aspects of this study helps to reinforce the idea that autism research should be and can be successfully conducted with, not just about, autistic people (C. Nicolaidis, Raymaker, D., McDonald, K., Dern, S., Ashkenazy, E., Boisclair, C., Robertson, S., Baggs, A., 2011). Two members of the AASPIRE team volunteered to be reviewers of my data and drafts of my thesis. One of the volunteers was/is a direct support staff person for Autistic people and a parent/supporter of an Autistic child. The other volunteer is a member of the Autistic community at large and has experience being a supporter themselves. Both AASPIRE team partners verified that the analysis results and first round of verification were accurate to their experiences in the Autistic community and the supporter community. They both stated that this work was important to both communities and the academy. Dissemination was also a topic of importance to both partners, as they both believed that getting the information out to the respective communities in a community-specific way was vital for the momentum of this research.

\section{Results}

Our sample consisted of 16 supporters, 12 of which were related to the autistic patient and 8 of which that were paid disability support staff. The majority of our sample was female (94\%) and approximately one half of the sample had supported only one autistic adult in a healthcare setting (44\%) while the approximate other half had supporter 2 or more autistic adults. See Table 1. 
Table 1. Participant characteristics, supporters $(N=16)$.

\begin{tabular}{lc}
\hline Interview mode & $N(\%)$ \\
In-person & $7(44 \%)$ \\
Telephone & $9(56 \%)$ \\
Age (in years) & Mean $52($ range $28-74)$ \\
Gender & $15(94 \%)$ \\
Female & $1(6 \%)$ \\
Male & $15(94 \%)$ \\
Race/ethnicity & $12(75 \%)$ \\
$\quad$ Non-Hispanic White & $8(50 \%)$ \\
Relationship to autistic adult(s) being supported (could have multiple roles) & \\
Family member & $7(44 \%)$ \\
Disability services provider & $5(31 \%)$ \\
Number of autistic adults participant has supported in healthcare settings & $4(25 \%)$ \\
$\quad$ I 9 & \\
I0 or more & \\
\hline
\end{tabular}

Participants described a range of healthcare experiences, even though the question specifically asked for an experienced negative event. However, there was differentiation in what the supporters were describing that involved whole-system-interaction factors and providerinteraction factors. More interestingly, it was the latent data that differentiated the most from the explicitly expressed content. Common themes were identified for each subset of data.

\section{Verification of Previous Findings}

The results for this study were significant because we were able to independently extract the same themes from the C. Nicolaidis et al. (2015) study that this research was based upon. To independently come up with the same themes in two separate study's is important because it verifies the results of both studies. Results included participant expression of experienced negative healthcare event could not be separated from describing the healthcare system and its interactions with other societal level factors. For instance, themes of lack of autism education, ASD discrimination, and health care system challenges were repeatedly described as being present, and often, at the core of why negative events were occurring. All of these factors interacting with each other produced the resolution or the suffering of the patient. Patient 
suffering often was described with markers that indicated that the supporters did their part in communicating the importance of the healthcare visit or in describing what should be done based on knowing the patient or being more educated in autistic traits (relevant to the visit) than the provider was.

\section{Latent Data}

Latent data was gathered from the participants answers to the interview question. Collection of latent data involves the analysis of how an answer is verbally constructed and trying to extract what the participant really meant. These extractions were also made by using context clues from the rest of the narration. Three major themes were found.

\section{Supporter Advocating for the Patient}

The first theme being the supporter advocating for the patient. As one participant noted:

“... and each time he came back to his [the physician's] manner of, um, you know, tell me, tell me what those letters are up on the wall. I told him that she [the patient], she didn't know how to read. and asked if we could switch to a, you know, a child's chart that had things facing different ways or something."

This represented how the supporter knew the patient had a lower reading level and advocated on behalf of the patient but might not necessarily know the patient on a personal level. Advocating for a patient, especially if the patient does not have the behavioral agency in that environment to advocate for themselves, is a vital step in the process of that patient receiving health care. If a supporter is not advocating on behalf of the patient when the patient needs them to do so, then they are not executing their job which can put the patient in an uncomfortable or high stakes situation. 


\section{Supporter Knowing the Patient}

The next theme was the supporter knowing the patient one participant described:

"I said, all right, fine, do it your way, go ahead. and so, they wanted to give him some pills. fine, give him the pills. So, he chewed the pills down, and drank the water, and that was all fine. well, as I predicted, it didn't work. the second they came in the room he was on high alert again, and there was no way they were gettin' close to him."

This narrative explains how the supporter knows the patient on an intimate level that allows the supporter to understand what will and won't work for the patient in regards to medical care and services. Knowing the patient is another unique factor in supporter advocacy. The supporter must know the patient on some level to understand how to support the patient in an effective and equitable way that not only gets the patient the medical attention they need in a timely manner, but also gives the patient the autonomy and respect they deserve.

\section{Supporter Minimizing the Negative Experiences of the Patient}

The final theme was the supporter minimizing the negative experience of the patient. One participant, S. said:

"I haven't really noticed bad or negative interactions. What I notice more of a negative thing is somewhat indifferent interactions. Impersonal interactions. I don't notice anything that would be harmful, neglectful, abusive, negative, mean. Nothin' like that. But more impersonal and indifferent."

This representation of latent minimizing demonstrates that the participant did not believe

or think that they had observed truly negative events within the healthcare appointments they had attended, even though previously S. had said (from the same interview):

"...the fellow who was at the psych unit, on his second stay he came away from there with a recommendation to try three new medications, and they should all be started at the same time. and I though, you know--and this is a guy who doesn't even like taking medication. And I thought...that's fine for you to prescribe that, and then let somebody else deal with the fall out. Because they're not gonna do any follow up care. But I see that as being very irresponsible... who even knows how the hell those things interact with each other." 
Minimization was more pronounced the more desperate the story became. Though desperation was did not become a major theme of this analysis, it did demonstrate a magnitude spectrum of minimization. For example, a participant was telling about how his daughter had a seizure and broke her front teeth out, needing surgery, but she would not be able to get in for months. The participant goes on to minimize his daughter' $s$ negative experience that is seemingly amplified through his desperate search for care:

"I need care for my daughter. I'll accept a lower level of care to get care. So, if they are thinking that they have to have all the right professionals and all of the right tools, and every single thing has to be exactly in place to be able to get her in, that's earliest they can do it--I would take fewer tools, less qualified individuals, a dirty environment if I could get in there in half the time. I don't care if there are banana peels on the floor! Bottom line is, she needs service!"

\section{$\underline{\text { Relationships between advocacy and knowledge }}$}

It should be noted that these two categories were able to co-occur and occur separately. Although, based on our findings, a supporter was more likely to advocate more aggressively for the patient if the supporter knew the patient on a more intimate level. In one interview a parent supporter mused about how her son was lucky to have a resilient "pitbull of a mother" especially when reflecting on one negative instance where a healthcare provider refused to treat her autistic son because he was autistic. The supporter here is summarizing how supporters have to be resilient and unrelenting in their task of assisting an autistic patient in receiving quality healthcare from their providers. Another supporter says;

"My experiences are that, you know, your best-case scenario is that the individual, or myself, or another parent is very knowledgeable, and the best-case scenario is if you just get a doctor to cooperate with you. That is your best-case scenario at this point in time." 
This supporter is again reinforcing the importance of supporter knowledge of the patient and advocacy for the patient with the physicians. The interviewee also makes an interesting comment about how physicians need to listen to and trust supporter in order to successfully provide quality healthcare for that specific patient.

\section{$\underline{\text { Relationships between advocacy, knowledge, and minimization }}$}

In our study we found the three major themes "Knowing the Patient," "Advocating for the Patient," and "Minimizing Negative Experiences." It was interesting to note how these three themes seemed to interact. Minimization themes were found in narratives that expressed advocating for and knowing the patient. A non-personal supporter could advocate for the patient and minimize. And a personal supporter could know and advocate for the patient while still minimizing the negative event. The level of intimacy did not consistently represent a connection for if minimization occurred or did not occur, however minimization was performed less frequently if the supporter was a family member of the patient.

A supporter could know the patient, advocate for them, and also minimize the negative experience. This was most often represented as a family member, so the trajectory of behavior would usually be they knew the patient intimately and advocated for them but did not minimize the experience. However, if minimization did occur it was co-occurring with sub-theme of desperation, but it did not appear enough to be considered saturated because family members were not minimizing to the extent that disability support staff were. We were curious about all these behavior trajectories and where they originate from. This is where considering deficitbased thinking about disability (i.e. the medical model of disability) and its influence, on the patient and the supporters of the patient, began. 


\section{Discussion}

Summary of findings

We began this study with interviews with supporters of Autistic adult patients with the intent of understanding the supporter's experience navigating a negative healthcare event while supporting the Autistic patient. Upon analysis, we independently discovered that we were able to extract the same themes that the original study by C. Nicolaidis et al. (2015) discovered. We also were able to extract new themes using a latent content analysis. These themes represented levels of intimacy with the patient (knowing the patient), levels of advocacy (advocating for the patient), and levels of coping strategy use (minimizing negative experiences). In this discussion I will touch on how the three major themes of this study interact and how the medical model might be affecting supporters.

\section{$\underline{\text { Medical Model }}$}

The medical model interprets disability "as tragic and problematic and the sole cause of disadvantage and difficulty" (Crow, 1996). To break this down and give context, the medical model is understood to view autism as a disorder that tragically and aggressively affects the life of the individual (Kapp, 2013). That because of the supposed debilitation that autism causes is “a 'condition', which needs appropriate 'treatment"” (Hogan, 2000). And finally, that treatment should be focused on the cure of, rehabilitation of, or the return to a behaviorally neurotypical standard of normalcy (Kapp, 2013). The medical model can also be referred to as the "deficit model" that poses autistic people (and other disabled individuals) as "severely limited" in their capacity to be healthy and functioning in social and physical environments (Robertson, 2010). 
Based on these conceptual understandings, it can be ascertained that the medical model certainly is a driving force behind the conceptualization of negative perspectives that manifest within any group that interacts with or discusses the autistic community.

My verification discussions with Jane and Joelle (the community partner verification volunteers) is where we began to connect the dots between the themes and ask larger system level questions about why these things would occur. Joelle commented on the interesting relationship between a supporter and a physician and how the power dynamics of that relationship might not only influence supporter behavior with the physician, but also the autistic patient. We also discussed how the medical model runs as a background framework that informs healthcare staff's approach to patients. This framework would influence anyone working in a healthcare setting, including a supporter of an autistic adult patient. Jane (as a family and paid support staff member) verified these assumptions and provided that she had indeed been witness to the influence of the medical model over paid supporters.

There is reason to believe that the medical model also could be influencing not only the perspective of autism as a disease that every autistic person needs to be cured of, but also be shaping how others interact with autistic people. According to Langan (2011), the medical model reinforces uneducated popular fears about autism, grief upon or potential diagnosis, and bitter disappointment in the lack of effective treatment options for curing autism. This negative impact can be presumed to affect behaviors and thoughts about autism and autistic people. This would give a reason to use cognitive coping mechanisms to deal with the cognitive dissonance of wanting to give aid the stigmatized population and being constantly barraged with negative stereotypes and attitudes about autism. 
In this study, we see how the subconscious minimization of negative experiences is affecting perceptions of negative events. In other words, we see the supporter describing negative experiences after they had stated they had not observed or experienced any negative events with an Autistic adult patient. The medical model could be a driving force behind this phenomenon because it "is one rooted in an undue emphasis on clinical diagnosis, the very nature of which is destined to lead to a partial and inhibiting view of the disabled individual" (Brisenden, 1986).This process is commonly referred to as 'dehumanization' and often is thought of as being inconsequential (Christoff, 2014). "When someone is dehumanized, they are implicitly or explicitly perceived as lacking qualities that are considered to be characteristically human" (Christoff, 2014). By taking the medical model perspective and considering autism as a "disease" we then categorized autistic characteristics as part of the disease as opposed to unique parts of the person (Kapp, 2013). Thusly, supporters are ascribing to the medical model belief and the practice of dehumanization, which is empirically proven to increase both avoidance behaviors such as bullying and harassment and personal negative self-concepts such as shame and guilt (Christoff, 2014). This inhibiting perspective would seem to lead to the use of coping mechanisms (such as minimization) to deal with subconscious negative affect regarding the stigmatized group, in this case Autistic patients.

Coping mechanisms refer to the things that all individuals do to alleviate strains that life offers (Pearlin, 1978). These mechanisms can be shared by those who are experiencing similar life events and also share similar traits (Pearlin, 1978). In our case, our population was supporters of Autistic adult patients. 12 of the 16 of our participants were familial supporters (or supporters who are parents, siblings, etc.) and 8 of the 16 were disability service providers (paid positions) - it must be noted that some of our participants held both roles. Participants who were 
only familial supporters did not participate in minimization as a coping method as often as the participants who were only disability service providers did. This brought us to the question of why this specific population of paid support staff was minimizing the negative experiences of Autistic patients?

According to a study done by M. Foster (2003) on hardy (or tough and resilient) vs. less hardy (or less tough and resilient) women and their experiences with discrimination, the hardy women were more likely to minimize their experiences of discrimination than the less hardy women. This begs the question of if the paid support staff were (or had to become) more psychologically resilient to work within a system that is driven by the medical model and with a community that constantly experiences discrimination (Baggs, 2008; Brown, 2012; Creigh, 2013; Sabrina, 2017). My hypothesis is yes that the paid support staff must either evolve to have higher rates of hardiness or resiliency and thus more often use minimization as a defense coping strategy to deal with the external pressures of their occupation and the internal stress of their cognitive dissonance.

\section{Limitations}

While this study had many strengths, it had it limitations, including the limitations of the original study. A maximal variation sampling technique was used in the original study to increase richness of the data. The U.S.-only sample was majority non-Latino white; therefore, findings also have a probability of not representing the experiences of those living in other countries or racial and ethnic minorities. Our sample was majority female (94\%) therefore giving a biased perspective. Half of our sample also had only supported one autistic adult in a healthcare setting therefore their experiences might not be representative of someone who supports multiple autistic adults in healthcare settings on a regular basis. The interview guide is a 
limiting factor because the original study aimed to gain the experience of the Autistic patient from patients, their supporters, and the physicians within a generalized healthcare setting, not the experiences of the supporters themselves. Thusly the questions were more generalized than focused on the experience of the supporter within a specifically negative healthcare event.

\section{Implications}

Our study has important implications. First, it is a demonstration of how using CBPR to approach research can not only enable autistic individuals to act as equal partners, but also positively impact the relevance, scope, and depth of the research. Second, more research needs to be done with supporters of autistic adults. A similar study with a more diverse sample and focused interviews on how supporters are experiencing these negative events in healthcare could yield new insights. Third, physicians need to be more aware of their power within a healthcare event and how their approach to the event can significantly impact the outcome. Fourth, paid disability support staff should be required to become familiar with the autistic adult patient's medical history and accommodations prior to the healthcare appointment. This allows for the supporter to know the patient and better advocate for them. Finally, disability service centers that dispense disability support staff need to require trainings on how to effectively support autistic adults in healthcare settings. Individualized approaches should be introduced to allow for equitable treatment of and interaction between the autistic adult and the support staff member.

At the end of our verification discussions, both Jane and Joelle insisted that dissemination of this work was vital. They both emphasized the importance of the research to the Autistic and supporter community at large. Therefore, the next steps for this research includes drafting a Short Report to submit to an Autism journal in the near future. However, it is important to stress the importance of continuing to fill this gap in the literature. Investigating the experience of 
supporters of autistic adults could lead us to discovering a better approach to supporting this community and assisting them in receiving the quality healthcare they deserve.

\section{Acknowledgements}

I would like to thank all of the AASPIRE team members for their invaluable insights, cooperation, and support in this project. I also thank Rebekah Hunter for help with data verification. I thank Jane Rake and Joelle Maslak for their volunteered time and priceless

perceptions and experiences. I thank Dr. Dora Raymaker and Dr. Christina Nicolaidis, who not only conducted the initial project that this study is based on but have been vital mentors to me through the course of my schooling and this project. 


\section{References}

Association, A. P. (2013). Diagnostic and statistic manual of mental disorders (Vol. 5th ed.): American Psychiatric Association.

Baggs, M. (2008). How did you figure out that this was a patter, and what made you realize it? Retrieved from https://ballastexistenz.wordpress.com/2008/07/26/how-did-you-figureout-that-this-was-a-pattern-and-what-made-you-realize-it/

Brisenden, S. (1986). Independent Living and the Medical Model of Disabiltiy. Disabiltiy, Handicap \& Society, 1(2), 173-178. doi:10.1080/02674648666780171

Brown, L. X. Z. (2012). Stop killing us. Retrieved from https://www.autistichoya.com/2012/04/stop-killing-us.html

Christoff, K. (2014). Dehumanization in organizational settings: some scientific and ethical considerations. Front Hum Neurosci, 8, 748. doi:10.3389/fnhum.2014.00748

Creigh, C. (2013, 14 November 2017). Stigma and Discrimination Retrieved from https://www.autismspectrumexplained.com/stigma--discrimination.html

Crow, L. (1996). Including All of Our Lives: Renewing the Social Model of Disabilty In C. Barnes, Mercer, L. (Ed.), Exploring the Divide (pp. 55-72): The Disability Press.

Foster, M. D., Dion, K. L. (2003). Dispositional Hardiness and Women's Well-Being Relating to Gender Discrimination: THe ROle of Minization Psychology Faculty Publications, 44.

Hogan, K., Llyewellyn, A. . (2000). The Use and Abuse of Models of Disability Disabilty \& Society, 15(1), 157-165.

Israel, B. A., Schulz, A. J., Parker, E. A., \& Becker, A. B. (1998). Review of community-based research: assessing partnership approaches to improve public health. Annu Rev Public Health, 19, 173-202. doi:10.1146/annurev.publhealth.19.1.173

Ji Young Cho, E.-H. L. (2014). Reducing Confusion about Grounded Theory and Qualitative Content Analysis: Similarities and Differences. The Qualitative Report, 19(62), 1-20.

Kapp, S., Gillespie-Lynch, K., Sherman, L. E., Hutman, T. . (2013). Deficit, Difference, or Both? Autism and Neurodiversity. Developmental Psychology, 49(1), 59-71.

Langan, M. (2011). Parental voices and controversies in autism. Disability \& Society, 26(2), 1932015. doi:10.1080/09687599.2011.544059

Nicolaidas, C. (2018, 2018). AASPIRE (Academic Autism Spectrum Partnership in Research and Education) CBPR. Retrieved from https://aaspire.org/about/cbpr/

Nicolaidis, C., Raymaker, D., McDonald, K., Dern, S., Boisclair, W. C., Ashkenazy, E., \& Baggs, A. (2013). Comparison of healthcare experiences in autistic and non-autistic adults: a cross-sectional online survey facilitated by an academic-community partnership. J Gen Intern Med, 28(6), 761-769. doi:10.1007/s11606-012-2262-7

Nicolaidis, C., Raymaker, D., McDonald, K., Kapp, S., Weiner, M., Ashkenazy, E., .. . Baggs, A. (2016). The Development and Evaluation of an Online Healthcare Toolkit for Autistic Adults and their Primary Care Providers. J Gen Intern Med, 31(10), 1180-1189. doi:10.1007/s11606-016-3763-6

Nicolaidis, C., Raymaker, D. M., Ashkenazy, E., McDonald, K. E., Dern, S., Baggs, A. E., . . Boisclair, W. C. (2015). "Respect the way I need to communicate with you": Healthcare experiences of adults on the autism spectrum. Autism, 19(7), 824-831. doi: $10.1177 / 1362361315576221$

Nicolaidis, C., Raymaker, D., McDonald, K., Dern, S., Ashkenazy, E., Boisclair, C., Robertson, S., Baggs, A. (2011). Collaboration Strategies in Nontraditional Community-Based 
Participatory Research Partnerships: Lessons From an Academic-Community Partnership With Autistic Self-Advocates. Progress in Community Health Partnerships, 5(2).

Pearlin, L. I., Schooler, C. (1978). The Structure of Coping. Journal of Health and Social Behavior, 19(1), 2-21.

Robertson, S. M. (2010). Neurodiversity, Quality of Life, and Autistic Adults: Shifting Research and Professional Focuses onto Real-Life Challenges. Disability Studies Quarterly, 30(1).

Roller, M. R. (2014). VERIFICATION: LOOKING BEYOND THE DATA IN QUALITATIVE DATA ANALYSIS. Retrieved from https://researchdesignreview.com/2014/04/30/verification-looking-beyond-the-data-inqualitative-data-analysis/

Sabrina. (2017). Autistic in the Workplace: Discrimination. Retrieved from https://strangerdarkerbetter.com/2017/09/19/autistic-in-the-workplace-discrimination/

Stewart, M. A. (1995). Effective physician-patient communication and health outcomes: a review. CMAJ, 152(9), 1423-1433.

Thomas, D. R. (2006). A General Inductive Approach for Analyzing Qualitative Evaluation Data. American Journal of Evaluation, 27, 237-246. doi:10.1177/1098214005283748 